\title{
17 Alpha Hydroxylase Enzyme Deficiency with Hyperaldosteronism
}

Ilkay kartal' Gonca Tamer ${ }^{1}$ Hasan Hüseyin Mutlu²

Istanbul Medeniyet University Göztepe Research and Education Hospital Department of Internal Medicine, Division of Endocrinology and Metabolism ${ }^{1}$

Istanbul Medeniyet University Göztepe Research and Education Hospital Department of Family Medicine²

\section{Background:}

Congenital adrenal hyperplasia $(\mathrm{CAH})$ resulting from 17 alpha hyroxylase enzyme deficiency (17OHD) is a rare autosomal recessive disorder (1). More than 150 cases were reported in the literature (2). Patients with $17 \mathrm{OHD}$ were reported to have hypoaldosteronism (3)
A 16 year old female referred to endocrinology outpatient clinic from family medicine depatment with the absence of a secondary sexual charasteristics and primary amenorrhea. On physical examination she had no pubic or axillary hair. She has tanner stage I breast development and female external genitalia. Her height was $158 \mathrm{~cm}$, weight $51 \mathrm{~kg}$ and blood pressure was $155 / 90 \mathrm{mmHg}$. Her karyotype was 46XX and bone age was nine years. Initial laboratory tests showed that serum glucose, urea, creatinin, sodium levels were normal; potassium level was low. Serum levels of 17 alpha hydroxyprogesterone (17-OHP), dehydroepiandosterone sulphate (DHEA-S), androstenodione, cortisol, plasma renin activity (PRA), estradiol (E2) were low and serum aldosterone, adrenocorticotropic hormone (ACTH), deoxycorticosterone $(\mathrm{DOC})$, luteinizing $(\mathrm{LH})$, follicle stimulating hormone (FSH) was high (Table I). All aldosterone and PRA values were obtained in upright position. Abdominal MRI showed rudimetary uterus and a nodullary development in the left adnexial area suggestive for ovary. The adrenal gland did not show significant adrenal hyperplasia and there was no mass lesion. Her blood pressure $(110 / 80 \mathrm{mmHg})$ and potassium $(3.9 \mathrm{mEg} / \mathrm{l})$ became normal after begining hydrocortisone tablet $10 \mathrm{mg}$ in the morning, $10 \mathrm{mg}$ at noon and $5 \mathrm{mg}$ in the evening. Subsequently the patient was started on cyclic estrogen for maturation of secondary sex characteristics. At the following visit we show that breast development was started but her blood pressure was $180 / 100 \mathrm{mmHg}$. Her potassium level was $3.4 \mathrm{meq} / \mathrm{L}$ we raised the total hydrocortisone dose to total $30 \mathrm{mg}$ a day and added $25 \mathrm{mg}$ sprinolactone. Few days later her self monitoring blood pressure results were between 160/100$140 / 90 \mathrm{mmHg}$. Amlodipin $10 \mathrm{mg}$ was started. Few days later blood pressure became normal. At the last visit her blood pressure was 120/80 $\mathrm{mmHg}$ serum potassium (3.9 meq/L), aldosteron (194 pg/ml), PRA $(0.762 \mathrm{ng} / \mathrm{ml} / \mathrm{h})$

Table 1. Baseline biochemical and hormonal test results

\begin{tabular}{|c|c|c|}
\hline Potassium $(\mathrm{meg} / \mathrm{L})$ & 2.9 & $3.5-5.2$ \\
\hline PRA upright (ng/ml/saat) & $<0.2$ & $0.2-6$ \\
\hline Aldosteron upright $(\mathrm{pg} / \mathrm{ml})$ & 385.45 & $20-220$ \\
\hline ACTH 08:00am $(\mathrm{pg} / \mathrm{ml})$ & 106 & $10-46$ \\
\hline Cortisol 08:00am $((\mu \mathrm{g} / \mathrm{ml}))$ & 1.75 & $6.2-19.4$ \\
\hline DHEA-S $(\mu \mathrm{g} / \mathbf{m l})$ & 6.33 & $25-250$ \\
\hline DOC (ng/dl) & 250 & $4-12$ \\
\hline 17-OHP (ng/dl) & 4.63 & 31-217 \\
\hline Total testosteron(ng/di) & 6.33 & $10-70$ \\
\hline LH（ $\mathbf{m I U} / \mathbf{m l})$ & 34 & $\begin{array}{l}\text { follicular: } 2.12-10.89 \\
\text { luteal:1.20-12.86 }\end{array}$ \\
\hline FSH (mIU/ml) & 89 & $\begin{array}{l}\text { follicular:3.85-8.78 } \\
\text { luteal:1.79-5.12 }\end{array}$ \\
\hline E2(pg/ml) & $<20$ & $\begin{array}{l}\text { follicular: } 27-122 \\
\text { luteal:49-291 }\end{array}$ \\
\hline
\end{tabular}

\section{Discussion:}

Patients with $17 \mathrm{OHD}$ have been reported to have hypoaldosteronism (3). We report a different variant of $17 \mathrm{OHD}$ with increased aldosteron and decreased renin production. We reviewed the literature and found at least 17 cases of $17 \mathrm{OHD}$ with normal aldosterone and 18 cases with elevated aldosterone levels. The explanation for that is salt retaining due to volume expansion effects of the high concentrations of DOC, with consequent transcriptional down regulation of aldosterone synthase (4). The mechanism of normal and high aldosterone levels remains unclear. One explanation for this different aldosterone levels can be the cross reaction of the antisera for aldosterone measurement (5). Beckman Coulter radioimmunoassay kit was used for aldosterone measurement in this case. The antibody used in this kit is highly specific for aldosterone. According to the direction of use of this kit; low reactivities were obtained with several molecules (corticosterone, 18-OH corticosterone, etc). Patients who have been regulary exposed to animals or received immunotherapy or diagnostic procedures utilizing immunoglobulins or immunoglobulin fragments may produce antibodies that interfere with immunoassays $(6,7)$; but there was no suspicion of having these antibodies in our patient. At the last visit her self-monitoring blood pressure results, serum potassium, aldosteron and PRA levels were all in normal limits as a result of hydrocortisone, sprinolactone, amlodipin treatment. We terminated cycling estrogen use for four weeks before these tests because estrogen, progesterone replacement may also interact with steroidogenesis. We thought that the radioimmunoassay in this study is reliable. Although the cross reaction possibility remains. Cases of $170 H D$ with hyperaldosteronism could be a variant of $17 \mathrm{OHD}$ and could be genetically determined. 